\title{
Impact of Health Education on Knowledge, Attitude and Practice Regarding Menstrual Hygiene among Pre University Female Students of a College Located in Urban Area of Belgaum
}

\author{
Pokhrel $\mathrm{S}^{1}$, Mahantashetti $\mathrm{N}^{2}$, Angolkar $\mathrm{M}^{3}$, Devkota $\mathrm{N}^{4}$ \\ ${ }^{1}$ (Department of Public Health, KLE University, India) \\ 2 (Jawaharlal Nehru Medical College, KLE University, India), \\ ${ }^{3}$ (Department of Public Health, KLE University, India) \\ ${ }^{3}$ (Department of Public Health, KLE University, India)
}

\begin{abstract}
Understanding about facts regarding menstruation and proper management of hygiene during menstruation is definitely one of the most essential ones for girls. The objective of our study was to assess the impact of health education on knowledge, attitude and practice on menstrual hygiene among PUC female students of college located in urban area of Belgaum. The study included all the PUC (arts and commerce stream) girls who had attained menarche and gave informed consent. Descriptive data were displayed in proportion, percentage and mean. Mc Nemar chi-square test was applied as a test of significance. Significance level was set at 5\%. There was a significant improvement in knowledge on nearly all menstruation relevant issues in pre-test compared to post-test. In the pre-test, only 75 (24.8\%) girls reported that they wash their genitalia in every visit to toilet whereas in the post-test, significant improvement was observed in their menstrual practice $(p<0.001)$. Similarly, the practice of bathing during menstruation was increased from $39.6 \%$ in pre-test to $99.0 \%$ in post-test which was found to be statistically significant $(P<0.001)$. The study also clearly pointed out the impact of health education in improving their knowledge and practices.
\end{abstract}

Keywords: Female Students, Health education, KAP, Menarche, Menstruation,

\section{Introduction}

The onset of menstruation is one of the most important changes occurring among girls during the adolescent years ${ }^{[1]}$. Menstruation is the cyclical shedding of the inner lining of the uterus, the endometrium, under the control of hormones of the hypothalamopituitary axis ${ }^{[2]}$. It is monthly bleeding for 3-5 days coming regularly every 28 days from puberty till menopause in the women's reproductive life. Menstrual cycle starts at the age of 13-15 years which marks the onset of puberty. Menstrual cycle ceases at the age of $45-50$ years ${ }^{[3]}$. A woman spends approximately 2100 days in menstruating that is almost 6 years of her life. These 6 years spread over a productive life of 50 years can potentially decide how healthy a women life will be. Most of the school going and pre-university girls are not aware of the fundamental facts about menstruation and puberty and very little attention is paid to the reproductive health of those girls ${ }^{[4]}$. Menstruation has often been dealt with secrecy in many cultures. Such perceptions coupled with poor and inadequate sanitary facilities have often kept girls from attending schools especially during periods of menstruation. The consequence of this is that many girls grow up with low self-esteem and disempowered from poor educational attainments. In India menstruation is surrounded with a long list of do's and don'ts with women. Menstruation becomes a central issue in her life. The importance of this phenomenon is not only the physiological but also social and religious significant is attached to it. Restrictions such as prohibition from religious activities, attending functions, cooking etc limits the daily activities and routines of women which is widely practiced in India. Most girls are ignorant about the physiology of menstruation and therefore the first experience of menstruation is of fear, shame and disgust. A fear is deep-rooted in adolescent girls that they will sin if they break these taboos. Due to these reasons girl's attitude and expectations about menstruation have became negative and this may result in poor menstrual hygiene which is associated with high prevalence of Reproductive Tract Infections (RTI's). ${ }^{[5]}$ A study conducted in Delhi revealed that majority $(86 \%)$ of the girls lack scientific knowledge about menstruation and puberty ${ }^{[6]}$. Adolescent girls often are reluctant to seek help regarding their menstrual problems. Understanding how to manage hygiene during menstruation is definitely one of the most essential ones for girls because poor maintenance of hygiene during menstruation results in several types of diseases such as RTI's, pelvic inflammatory diseases, urinary tract infections etc. which may result in infertility of the girls. The adolescent girls should be educated about the facts of menstruation, physiological implications, and proper hygienic practices with selection of disposable sanitary menstrual absorbent. This can be achieved through schools and colleges by providing health education to them. Hence this study was carried out in a college by providing health education on menstrual hygiene and assessing its impact. 


\section{Materials And Methods}

An intervention study design was used in carrying out this study. The study was conducted in RLS College in an urban area of Belgaum district. Data was collected from pre university college (PUC) female students studying in an urban college in Belgaum. Female students studying in PUC who had attained menarche and those who gave consent were included in the study whereas students who attempted pre-test questionnaires but not post test were excluded from the study. The study was conducted for a period of 11 months from 1st February, 2012 to 30th December, 2012. There were total 315 girls including both PUC $1^{\text {st }}$ and PUC $2^{\text {nd }}$ year. Among them 303 participants enrolled in this study. The attrition was due to absenteeism and denial for consent. The data was collected by self administered pretested questionnaire before and after the health education intervention. Prior to data collection, ethical clearance was obtained from institutional ethics committee of KLE University. After approval of ethical clearance, permission was obtained from the college authorities. Pilot study was conducted among $10 \%$ of total students from each class, before undertaking the major study to test the interview schedule and to assess any constraints that could arise and would need to be addressed during this study. Also, the approximate time taken for completing the self administered questionnaire was identified during the pilot study. Following the pilot study, the questionnaire was finalized and made ready for use. The information was obtained by following procedures:

a. Initial assessment stage: This stage served to assess knowledge attitude and practice about menstrual hygiene among female students who agreed to participate in the study were informed about the nature and purpose of the study before implementation of the program by the tools. In this stage, data was collected by using pretested self administered questionnaire.

b. Health education intervention stage: Its main aim was to improve knowledge and practice about menstrual hygiene among female students. The methods of teaching used in program were lecture followed by group discussions as well as posters were used as the media for the program. This was done in the class room at the college. There were total 8 sections including both arts and commerce. In each section, 1 hour lecture was conducted in a particular day for every week and the total health education session was completed within 2 months. Health Education practice covered the following topics:

- Introduction of Menstruation

- Menstrual cycle

- Problems associated with menstruation

- Importance of menstrual hygiene and management during menses

c. Evaluation stage: In order to assess the impact of the program, a post-test was done after three months of health education session using the same tool (Pre tested Self administered questionnaire). The post test results were compared to the pretest results.

All the codes corresponding to the responses were entered in Statistical Package for Social Sciences version 20 (SPSS-20). The analysis was done and displayed in proportion, percentage and mean. For the test of significance, McNemar chi-square test was used $(\mathrm{P}<0.05)$.

\section{Results}

Table 1 illustrates the socio-demographic variables. Of 303 total respondents, $43.6 \%$ of girls belonged to the age of 17 years followed by 18 years $(28.4 \%)$ and 16 years $(28.1)$. The mean age of the respondents was $17 \pm 0.752$ years. Similarly, $83.5 \%$ of them belonged to the Hindu religion followed by Muslim $(8.3 \%)$ and Christian (8.3\%).Total of $49.5 \%$ of respondents father were involved in private service, $30.7 \%$ were involved in government service, followed by farmer $(16.5 \%)$, labor and factory worker $1.7 \%$ each. The majority $(40.3 \%)$ of the mothers were having education up to primary level followed by secondary $(26.4 \%)$, illiterate $(21.5 \%)$, graduate or higher $(9.9 \%)$ and PUC $(2.0 \%)$. Majority $(40.3 \%)$ of female attained menarche at the age of 14 years followed by 13 years(36.6\%), 15 years( $13.2 \%), 12$ years(6.6\%),11 years and 16 years being equal i.e. $1.7 \%$ each. In the same study, the mean age at menarche was $13.62 \pm 0.91$ years.

Table 2 shows the comparison between pre-post knowledge about menstruation among students. Present study showed 52.1\% had correct knowledge (i.e. normal physiological process) before the intervention where as it was increased to $96 \%$ after the health education intervention ( $\mathrm{P}$-value $=<0.001$ ). Regarding the organ of menstrual blood flow, 29.7\% had given correct answer (i.e. uterus) at baseline which increased to $90.4 \%$ after post test; where as $65.3 \%$ didn't know the answer, which was decreased to $9.6 \%$ in post test. Concerning the knowledge on duration of normal menstruation, $68.6 \%$ had correct knowledge (i.e.5 days) in pretest which increased to $92.1 \%$ in post test $(\mathrm{P}$-value $=<0.024)$. Majority i.e. $78.5 \%$ of the students had correct knowledge on interval between 2 menstrual cycles during pre test which increased to $95.0 \%$ in post test. Also $11.6 \%$ of the respondents did not know anything about the interval between 2 menstruation cycles which was reduced to $2.3 \%$ in post test.

Table 3 describes about perceptions \& experiences of menstruation. On asking the question on feeling about first menstruation, $37.3 \%$ felt discomfort followed by scared $(33.0 \%)$, indifferent $(28.1 \%)$ and others 
(1.7\%). Similarly, $76.9 \%$ of the participants were having regular pattern of menstruation whereas $23.1 \%$ had irregular pattern of menstruation. Majority $(60.1 \%)$ of the participants were having normal duration (i.e. 5 days) of menstruation in their cycle followed by 3 days (18.5\%), 7 days (14.9), more than 7 days (6.6\%). Majority of the girls i.e. $78.5 \%$ had the problems associated with menstruation. Among them $36.1 \%$ reported back pain, $32.4 \%$ reported weakness followed by severe abdominal pain i.e. $29.4 \%$ and vomiting $2.1 \%$. Among those girls who had problem, only $12.2 \%$ sought the treatment for menstrual disorder.

Table 4 reveals the distribution of participants according to practice regarding menstrual hygiene. Of 303 respondents, $56.4 \%$ used sanitary pad, $28.7 \%$ used new cloth, $13.2 \%$ used old cloth and $1.7 \%$ used tampon as a absorbent during menstruation in pretest whereas the use of sanitary pad increased to $90.8 \%$, followed by new cloth $(6.6 \%)$ and old cloth $(2.6 \%)$ in post test (P- Value $<0.001)$. Among total respondents who used cloth as pad, correct method used for cleaning (i.e. soap and water) was practiced by $88.18 \%$ respondents during pretest, however all $(100 \%)$ of the respondents who were using cloth as a pad used the correct method of cleaning in post test ( $\mathrm{p}$-value $=<0.001)$. Similarly, correct practice of drying the cloth used as pad was practiced by $23.62 \%$ during pre test which increased by $100 \%$ in post test ( $\mathrm{p}$-value $=<0.001$ ). Likewise, $47.2 \%$ of the respondents changed pad twice a day followed by thrice(28.1\%), once( $11.6 \%)$, four times and more than four times being equal in percentage $(6.6 \%)$ during pretest, whereas in post test majority $(89.4 \%)$ changed pad thrice followed by twice $(7.3 \%)$ and four times $(3.3 \%)(\mathrm{P}$-value $=<0.001)$. There was significant increase in college attendance from pretest i.e. $91.7 \%$ to post test i.e. $96.7 \%$. Similarly, there was significant improvement in correct disposal of pad (i.e. in dustbin) from $66.7 \%$ in pretest to $97.3 \%$ in post test (p-value $=<0.001$ ). There was significant increase in cleaning of genitalia i.e. from $24.8 \%$ in pretest to $96.0 \%$ in post test. Also, there was significant increase in bathing i.e. $39.6 \%$ in pretest to $99.0 \%$ in post test.

Table 5 describes the restriction during menstruation, there was no significant difference observed in restriction on household works and religious activities from pretest to post test ( $>0.05)$. However significant difference was observed in restriction in moving freely and entering kitchen from pretest to post test. $(p<0.001)$

Fig 1 describes the distribution of participants according to awareness before attaining menarche. Of 303 respondents, $62 \%$ of them were aware about menstruation before attaining menarche and rest of them were not aware about it. Fig 2 describes the distribution of participant according to source of information about menstruation, majority of the respondents heard from mothers i.e. $71 \%$, followed by friends i.e. $19 \%$ and rest from teacher i.e. $10 \%$.

\section{Discussion}

In our study, the mean age of the respondents was $17 \pm 0.752$. The study conducted in Nigeria in 2006, reported the mean age of the school girls was $14.9 \pm 1.7$ years ${ }^{[7]}$. Similarly study conducted in Sokoto, Nigeria also reported the mean age of adolescents was $16.75 \pm 1.25$ years of being majority in the age group of $15-17$ years ${ }^{[8]}$. In our study $49.5 \%$ fathers of respondents were private workers, $30.7 \%$ were government workers, and $16.5 \%$ were farmers followed by $1.7 \%$ factory workers and $1.7 \%$ labor respectively. Similar study conducted in west Bengal showed that $45 \%$ were farmers followed by businessman, service holder and daily wage laborer ${ }^{[9]}$. Our study showed that majority of the mothers of research participants have attained primary education $(40.3 \%)$ followed by secondary education $(26.4 \%)$, illiterate $(21.5 \%)$ and so on. Similarly, the study conducted in Nigeria in 2006 reported that majority of the mothers of adolescent girls have attained tertiary education $(47.5 \%)$ followed by secondary (30.7\%), primary $(14.9 \%)$ and so on ${ }^{[10]}$. Study conducted in Sokoto, Nigeria also revealed in his study that majority of the mothers have attained tertiary level of education $(47 \%)$ followed by secondary education $(28 \%)$, primary education $(3 \%)$ and so on ${ }^{[11]}$. In our study, the mean age at menarche was found to be $13.62 \pm 0.913$ years. Similarly, a study conducted in Nigeria reported that the mean age of adolescent girls at menarche was 14.18 years ${ }^{[8]}$. Another study conducted in Nagpur in 2011 reported that the mean age of menarche in the adolescent girls was $12.85 \pm 0.867$ years ${ }^{[12]}$. This study revealed that $62.0 \%$ of the total respondents were aware about menstruation before attaining menarche. Similar to this, a study conducted in West Bengal reported that $67.5 \%$ girls were aware about menstruation prior to attainment of menarche ${ }^{[9]}$. Similarly, study conducted in Uttarakhand also reported that $64.5 \%$ adolescent girls were aware about menstruation prior to the attainment of menarche ${ }^{[13]}$. Our study revealed that mothers of the respondents were the major source of information i.e. $70.7 \%$ followed by friends $18.6 \%$ and teacher $10.6 \%$. Consequent to our study, a study conducted in South India reported in his study that mother were the main source of information $54.00 \%$ followed by friends $35.3 \%$ and so on ${ }^{[14]}$. Similarly study conducted in Gujarat reported that the major source of information was the mother $60.7 \%$ followed by older sisters $15.8 \%$, however teachers and others played a small role in it ${ }^{[15]}$. In our study we found the knowledge on cause of menstruation was poor among participants i.e. only $52.1 \%$ of them knew that menstruation is normal physiological process among adolescent girls before health education intervention but later the knowledge was significantly increased to $96 \%$ after intervention. Similar findings were reported in a study conducted in Zagazig City ${ }^{[16]}$. Similarly, our study showed that there was significant improvement after health education intervention in the knowledge regarding 
the organ of blood flow during menstruation as only $29.75 \%$ of the respondents correctly reported it as uterus followed by abdomen $(3.3 \%)$, intestine $(1.7 \%)$ and remaining were not aware about it before intervention but was increased to $90.4 \%$ after intervention. Similarly, in a study conducted among adolescent girls in Varanasi district (UP), 43.5 per cent of the girls correctly responded uterus as the organ from where the menstrual blood comes ${ }^{[3]}$. In a study conducted among the rural adolescent girls of Nepal, 25.3 per cent of the girls reported uterus as the organ of bleeding during menstruation whereas 32 per cent, 26.7 per cent and 16 per cent said the fallopian tube, vagina and urinary bladder respectively ${ }^{[17]}$. In our study, the knowledge on duration of normal menstruation among the respondents was significantly increased from $68.6 \%$ to $92.1 \%$ who correctly identified it as 5 days. Similarly, knowledge on interval between 2 menstruation cycles was significantly increased from $78.5 \%$ to $95.00 \%$ who correctly reported it as $28-30$ days. These results were in the line with a study conducted in Karnataka that reported the knowledge on interval between two menstrual cycles was significantly increased from $77.2 \%$ to $91.8 \%{ }^{[18]}$. On questioning about the reaction to first menstruation among respondents, majority i.e. $37.3 \%$ told that they felt discomfort followed by scared $33 \%$, indifferent $28.1 \%$ and others. The findings from a study conducted in Nepal reported that $96.7 \%$ of the respondents were upset and tensed whereas around $3 \%$ told that they felt normal ${ }^{[17]}$. Our study revealed that majority $75 \%$ of the respondents had menstrual duration between 5 to 7 days, followed by 3 days $18.5 \%$ and more than 7 days $6.6 \%$. Similarly, a study conducted in Gujjar pointed out that of total 131 subjects who were having menstruation, $78.6 \%$ subjects reported their duration of menstruation between 0 to 6 days while rest of them reported their duration between 7 to 12 days ${ }^{[19]}$. Another study conducted in Nigeria reported that majority (62\%) of the respondents were having menstrual duration between 2-4 days followed by $33 \%$ between $5-7$ days ${ }^{[8]}$. Our findings showed that there was significant increase from pre to post intervention in the use of sanitary pad i.e. from $56.4 \%$ to $90.8 \%$. Similar findings was observed in the study conducted in Nigerian school girls where there was significant increase in the use of sanitary pad after receiving training on menstrual hygiene i.e. from $61.7 \%$ to $75.1 \%{ }^{[7]}$. Likewise a study conducted in Maharashtra also reported that the practice of using ready-made pads increased significantly from $5 \%$ to $25 \%$ after health education intervention ${ }^{[20]}$. Likewise, in our study, majority i.e. $88.18 \%$ of the participants were using soap and water to clean the cloth and remaining didn't do so before intervention however this practice was significantly increased to $100 \%$ after intervention. With regard to drying the clothes, in the pretest period, only $23.62 \%$ girls sundried the clothes which increased to $100 \%$ in the post test period. Corresponding with the current findings, a study conducted in Mumbai reported that in the pre-test, it was observed that 51.28 per cent of the girls washed their cloths only with water, 4.27 per cent of them sundried their cloths, while in the post-test preceding health education, significant improvements were observed in their practices $^{[21]}$. Similarly in the pretest phase of our study , $47.2 \%$ girls reported that they change the pad only twice a day while in the post test, it decreased to $7.3 \%$, their by showing improved menstrual hygiene and practice following health education. With regard to final disposal of pad, in the pre-test period, $66.7 \%$ girls threw it in the dustbin, $19.8 \%$ girls burnt it, $10.2 \%$ girls drained it and remaining of them threw it by the roads. In the post-test period, $97.3 \%$ girls reported that they threw the used pads in the dustbin. Such menstrual practices were also reported in another study among adolescent school girls in Nepal where regarding final disposal of the menstrual materials, 43 per cent of the girls buried their absorbent materials followed by 35 per cent threw with other wastes and 19 per cent burnt the materials ${ }^{[22]}$. Regarding the practice on cleaning genitalia only $24.8 \%$ girls reported of cleaning genitalia in pretest whereas it was increased to $96.0 \%$. This difference was found to be statistically significant i.e. $(\mathrm{P}<0.001)$. In line with our findings, a study conducted in Persian adolescent girls also reported that the impact of health education session on genital hygiene was found to be significant in experimental group as compared to control group ${ }^{[23]}$. The practice of bathing during menstruation was increased from $39.6 \%$ in pretest to $99.0 \%$ in post-test in our study. This difference was found to be statistically significant $(p<0.001)$. Similar findings were also observed in the studies done among female secondary school students of Zagazig City \& adolescent girls of Kalamboli, Mumbai ${ }^{[16,21]}$ In our study majority of the girls i.e. $78.5 \%$ had the problems associated with menstruation, among them $36.1 \%$ reported back pain, $32.4 \%$ reported weakness followed by severe abdominal pain i.e. $29.4 \%$ and vomiting $2.1 \%$. Similar study conducted in east Delhi showed Dysmmenorrhea was prevalent in majority of girls i.e. $3.75 \%{ }^{[24]}$. Similar findings were also observed in a study done among college students in urban Ile-Ife, Nigeria ${ }^{[8]}$

\section{Conclusion}

The findings led to the conclusion that the students have deficient knowledge, various misconceptions and inadequate practices regarding menstruation and its management in pretest. However the knowledge and practices were significantly improved in post test. This clearly points out that health education is improving their knowledge and practices. Taking into account the health implications and prevailing socio-cultural and economic factors, there is an urgent need for intensifying effective strategies to persuade the adolescent school girls to adopt healthy menstrual practices. It is recommended that this type of study should be replicated with large sample selected from different geographical areas in order to generalize the findings of the study. 
Moreover, the education regarding reproductive health and menstrual hygiene should be the part of curriculum for adolescent girls.

\section{References}

[1]. Swati Y. Bhave. Course Manual for Adolescent Health Part- II. Indian Perspective, IAP-ITPAH, 319-332, 6-9,115-121.(6)

[2]. Deo DS, Ghattargi $\mathrm{CH}$. Perceptions and practices regarding menstruation. A comparative study in urban and rural adolescent girls. Indian Journal of Community Medicine 2005; 30:PP( 33-34)(7)

[3]. Singh Sp, Maya S, Meenakshi, Sen AP. Knowledge assessment regarding puberty and menstruation among secondary school girls of district Varanasi, Uttar Pradesh. Indian J Pre Med. 2006; 37(1): 9-14(8)

[4]. Fernandes M, Khurana I, Mahapatra R. infochange Public health. 41\% of women unprepared for menstruation.2008 Nov(9)

[5]. Garg R, Goyal S, Gupta S. India Moves Towards Menstrual Hygiene: Subsidized Sanitary Napkins for Rural Adolescent GirlsIssues and Challenges. Matern Child Health J(2012); 16:767-774(11)

[6]. Baridalyne N, Reddaiah PV. Menstruation: Knowledge, Beliefs and Practices of women in the reproductive age group residing in an urban resettlement colony of Delhi. Health and Population Perspectives and Issues. 2004; 27(1): 9-16(15)

[7]. Aniebue U U, Aniebue NP, Nwankwo O T. The impact of pre-menarcheal training on menstrual practices and hygiene of Nigerian school girls. Pan Africa Medical Journal. 2009; 2(9)(16)

[8]. Esimai O A, Esan G O. Awareness of menstrual abnormality amongst college students in urban area of Ile-Ife, Osun State, Nigeria. Indian J Community Med 2010;35:63-6(17)

[9]. Dasgupta A, Sarkar M. Menstrual hygiene: How Hygienic is the Adolescent Girl? Indian J Community Med 2008; 33(2): 77$80 \mathrm{P}(34)$

[10]. Aniebue U U, Aniebue NP, Nwankwo O T. The impact of pre-menarcheal training on menstrual practices and hygiene of Nigerian school girls. Pan Africa Medical Journal. 2009; 2(9): 1-9(16)

[11]. Oche M O, Umar A S, Gana G J, Ango J T. Menstrual health: the unmet needs of adolescent girls' in Sokoto, Nigeria. Scientific Research and Essays. 2012. 7(3), pp. 410-418(19)

[12]. Thakre BS, Thakre SS, Reddy M, Rathi N, Pathak K, Ughade S. Menstrual Hygiene: Knowledge and Practice among Adolescent School Girls of Saoner Nagpur District. Journal of Clinical and Diagnostic Research 2011 October; 5(5): 1027-1033P(36)

[13]. Juyal R, Kandpal SD, Semwal J, Negi KS. Practice of menstrual hygiene among adolescent girls in a district of Uttarakhand. Indian Journal of Community Health. 2012; 24(2):124-128(28)

[14]. Omidvar S, Begum K. Factors Influencing Hygienic Practices During Menses Among Girls From South India- A Cross Sectional Study: International Journal of Collaborative Research on Internal Medicine \& Public Health.2010; 2(12): 411-423(30)

[15]. Tiwari, H., U. N. Oza, and R. Tiwari. Knowledge, attitudes and beliefs about menarche of adolescent girls in Anand district, Gujarat. Eastern Mediterranean health journal. 2006; 12(3/4):428-433(33)

[16]. Allah A. S. E, Elsabagh M.E.E. Impact of Health Education Intervention on Knowledge and Practice about Menstruation among Female Secondary School Students in Zagazig City. Journal of American Science. 2011; 7(9): 737-747(39)

[17]. Adhikari P, Kadel B, Dhungel S1, Mandal. A Knowledge and practice regarding menstrual hygiene in rural adolescent girls of Nepal. Kathmandu University Medical Journal 2007; Vol. 5, No. 3, (19): 382-386(25)

[18]. Rao RS, Lena A, Nair NS, Kamath V, Kamath A. Effectiveness of reproductive health education among rural adolescent girls: A school based intervention study in Udupi Taluk, Karnataka. Indian J Med Sci. 2008 ;62(11):439-43(27)

[19]. Rajni Dhingra, Anil Kumar, Manpreet Kour (2009): Knowledge and Practices Related to Menstruation among Tribal (Gujjar) Adolescent Girls Ethno-Med, 3(1): 43-48.(40)

[20]. Dongre AR, Deshmukh PR and Garg BS. The Effect of Community-Based Health Education Intervention on Management of Menstrual Hygiene among Rural Indian Adolescent Girls. World Health \& population 2007; 9(3): 48-54P(32)

[21]. NemadeD, AnjenayaS, GujarR. Impact of Health Education on Knowledge and Practices about Menstruation among Adolescent School Girls of Kalamboli, Navi, Mumbai. HPPI,2009; 32 (4): 167-175(31)

[22]. Water Aid's Mission, Nepal. (2009). Is menstrual hygiene and management an issue for adolescent school girls? Available at: http://www.wateraid.org/documents/plugin documents/wa nep . Assessed on July 04, 2010.(26)

[23]. Fakhri M, Hamzehgardeshi Z, Golchin $\bar{N}$, Komili A. Promoting menstrual health among Persian adolescent girls from low socioeconomic backgrounds: a quasi-experimental study. BMC Public Health 2012, 12:193(24)

[24]. Parvathy N, Vijay LG, Kanan. Awareness and practices of menstruation and pubertal changes amongst unmarried female adolescents in rural area of east Delhi. Ind J Comm medicine. 2007; 32(2): 156-157(41)

Table 1: Distribution of Participants According to Demographic Characteristics

\begin{tabular}{|c|c|c|}
\hline Variables & Frequency & Percentage \\
\hline \multicolumn{3}{|l|}{ Age } \\
\hline 16 & 85 & 28.1 \\
\hline 17 & 132 & 43.6 \\
\hline 18 & 86 & 28.4 \\
\hline Mean age of the respondent & \multicolumn{2}{|c|}{$17 \pm 0.752$} \\
\hline \multicolumn{3}{|l|}{ Religion } \\
\hline Hindu & 253 & 83.5 \\
\hline Muslim & 25 & 8.3 \\
\hline Christian & 25 & 8.3 \\
\hline \multicolumn{3}{|l|}{ Occupation of father } \\
\hline Labor & 5 & 1.7 \\
\hline Private service & 150 & 49.5 \\
\hline Government service & 93 & 30.7 \\
\hline Factory worker & 5 & 1.7 \\
\hline farmer & 50 & 16.5 \\
\hline \multicolumn{3}{|c|}{ Educational status of the mother } \\
\hline Illiterate & 65 & 21.5 \\
\hline Primary & 122 & 40.3 \\
\hline Secondary & 80 & 26.4 \\
\hline
\end{tabular}


Impact of Health Education on Knowledge, Attitude and Practice Regarding Menstrual Hygiene

\begin{tabular}{|l|c|c|}
\hline PUC & 6 & 2.0 \\
\hline graduate or higher & 30 & 9.9 \\
\hline $\begin{array}{l}\text { Mean age at Menarche } \\
\text { Mean } \pm \text { SD (range) }\end{array}$ & & $13.62 \pm 0.91$ \\
\hline
\end{tabular}

Table 2 Comparison between Pre-Post Knowledge about Menstruation among Students in the Study

\begin{tabular}{|c|c|c|c|c|c|}
\hline \multirow{2}{*}{ Variables } & \multicolumn{2}{|c|}{ Pretest } & \multicolumn{2}{|c|}{ Post test } & \multirow{2}{*}{ P-value } \\
\hline & Number & $\%$ & Number & $\%$ & \\
\hline \multicolumn{6}{|c|}{ Knowledge regarding cause of menstruation } \\
\hline Correct knowledge & 158 & 52.1 & 291 & 96 & \multirow{3}{*}{$<0.001$} \\
\hline Incorrect Knowledge & 45 & 14.9 & 0 & 0 & \\
\hline Don't know & 100 & 33.0 & 12 & 4 & \\
\hline \multicolumn{6}{|c|}{ Knowledge regarding the organ of blood flow during menstruation } \\
\hline Correct Knowledge & 90 & 29.7 & 274 & 90.4 & \multirow{3}{*}{$<0.001$} \\
\hline Incorrect Knowledge & 15 & 5.0 & 0 & 0 & \\
\hline Don't Know & 198 & 65.3 & 29 & 9.6 & \\
\hline \multicolumn{6}{|c|}{ Knowledge on duration of normal menstruation } \\
\hline Correct Answer & 208 & 68.6 & 279 & 92.1 & \multirow[t]{2}{*}{$<0.024$} \\
\hline Wrong Answer & 95 & 31.4 & 24 & 7.9 & \\
\hline \multicolumn{6}{|c|}{ Knowledge on interval between 2 menstruation cycle } \\
\hline Correct Answer & 238 & 78.5 & 288 & 95.0 & \multirow{3}{*}{$<0.001$} \\
\hline Wrong Answer & 30 & 9.9 & 8 & 2.7 & \\
\hline Don’t Know & 35 & 11.6 & 7 & 2.3 & \\
\hline
\end{tabular}

Table 3 Frequency Distribution of Menstrual Pattern of Study Participants

\begin{tabular}{|c|c|c|}
\hline Menstrual pattern & Number & Percentage \\
\hline \multicolumn{3}{|c|}{ Reaction to first menstruation } \\
\hline Scared & 100 & 33.0 \\
\hline Discomfort & 113 & 37.3 \\
\hline Indifferent & 85 & 28.1 \\
\hline Others & 5 & 1.7 \\
\hline \multicolumn{3}{|l|}{ Pattern of menstruation } \\
\hline Regular & 233 & 76.9 \\
\hline Irregular & 70 & 23.1 \\
\hline \multicolumn{3}{|c|}{$\begin{array}{l}\text { Duration of Menstruation in respondent's } \\
\text { menstrual cycle }\end{array}$} \\
\hline 3 days & 56 & 18.5 \\
\hline 5 days & 182 & 60.1 \\
\hline 7 days & 45 & 14.9 \\
\hline More than 7 days & 20 & 6.6 \\
\hline \multicolumn{3}{|c|}{ Problems associated with menstruation } \\
\hline Yes & 238 & 78.5 \\
\hline No & 65 & 21.5 \\
\hline \multicolumn{3}{|l|}{ if yes what is the problem } \\
\hline Vomiting & 5 & 2.1 \\
\hline Weakness & 77 & 32.4 \\
\hline Severe abdominal pain & 70 & 29.4 \\
\hline Back pain & 86 & 36.1 \\
\hline \multicolumn{3}{|c|}{ Treatment for menstrual disorder } \\
\hline Yes & 29 & 12.2 \\
\hline No & 209 & 87.8 \\
\hline
\end{tabular}

Table 4 Distribution of Participants according to Practice Regarding Menstrual Hygiene before and after Intervention

\begin{tabular}{|c|c|c|c|c|c|}
\hline \multirow{2}{*}{ Variables } & \multicolumn{2}{|c|}{ Pre test } & \multicolumn{2}{|c|}{ Post test } & \multirow{2}{*}{ P-value } \\
\hline & Number & $\%$ & Number & $\%$ & \\
\hline \multicolumn{6}{|c|}{ Absorbent used during menstruation } \\
\hline Tampon & 5 & 1.7 & 0 & 0 & \multirow{4}{*}{$<0.001$} \\
\hline Sanitary pad & 171 & 56.4 & 275 & 90.8 & \\
\hline New cloth & 87 & 28.7 & 20 & 6.6 & \\
\hline Old cloth & 40 & 13.2 & 8 & 2.6 & \\
\hline \multicolumn{6}{|c|}{ Method used for cleaning cloth } \\
\hline Soap and water & 112 & 88.18 & 28 & 100.0 & \multirow{3}{*}{$<0.001$} \\
\hline Only water & 10 & 7.87 & 0 & 0 & \\
\hline Throw it away & 5 & 3.93 & 0 & 0 & \\
\hline \multicolumn{6}{|c|}{ Practice of drying cloth used as a pad } \\
\hline Press it & 15 & 11.8 & 0 & 0 & \multirow{3}{*}{$<0.003$} \\
\hline Sundry & 30 & 23.62 & 28 & 100.0 & \\
\hline Hang inside the house & 82 & 64.58 & 0 & 0 & \\
\hline
\end{tabular}


Impact of Health Education on Knowledge, Attitude and Practice Regarding Menstrual Hygiene

\begin{tabular}{|c|c|c|c|c|c|}
\hline \multicolumn{6}{|c|}{ Changing of pad in a day } \\
\hline Once & 35 & 11.6 & 0 & 0 & \multirow{5}{*}{$<0.001$} \\
\hline Twice & 143 & 47.2 & 22 & 7.3 & \\
\hline Thrice & 85 & 28.1 & 271 & 89.4 & \\
\hline Four times & 20 & 6.6 & 10 & 3.3 & \\
\hline More than 4 times & 20 & 6.6 & 0 & 0 & \\
\hline \multicolumn{6}{|c|}{ Attending college during menstruation } \\
\hline Yes & 278 & 91.7 & 293 & 96.7 & \multirow{2}{*}{$<0.015$} \\
\hline No & 25 & 8.3 & 10 & 3.3 & \\
\hline \multicolumn{6}{|c|}{ Disposal of pad after use } \\
\hline Dustbin & 202 & 66.7 & 295 & 97.3 & \multirow{5}{*}{$<0.001$} \\
\hline Drain & 31 & 10.2 & 0 & 0 & \\
\hline Toilet & 5 & 1.7 & 0 & 0 & \\
\hline Burn & 60 & 19.8 & 5 & 1.7 & \\
\hline Throw away & 5 & 1.7 & 3 & 1.0 & \\
\hline \multicolumn{6}{|c|}{ Cleaning of genitalia at every visit to toilet } \\
\hline Yes & 75 & 24.8 & 291 & 96.0 & \multirow{2}{*}{$<0.001$} \\
\hline No & 228 & 75.2 & 12 & 4.0 & \\
\hline \multicolumn{6}{|c|}{ Bathing during menstruation } \\
\hline Yes & 120 & 39.6 & 300 & 99.0 & \multirow{2}{*}{$<0.001$} \\
\hline No & 183 & 60.4 & 3 & 1.0 & \\
\hline
\end{tabular}

Table 5: Restrictions and Practices during menstruation

\begin{tabular}{|c|c|c|c|c|c|}
\hline \multirow{2}{*}{ Variables } & \multicolumn{2}{|c|}{ Pretest } & \multicolumn{2}{|c|}{ Post test } & \multirow{2}{*}{ P-value } \\
\hline & Number & $\%$ & Number & $\%$ & \\
\hline \multicolumn{6}{|c|}{ Restriction in household works } \\
\hline Yes & 47 & 15.5 & 42 & 13.9 & \multirow{2}{*}{0.063} \\
\hline No & 256 & 84.5 & 261 & 86.1 & \\
\hline \multicolumn{6}{|c|}{ Restriction in moving freely } \\
\hline Yes & 43 & 14.2 & 6 & 2.0 & \multirow[t]{2}{*}{$<0.001$} \\
\hline No & 260 & 85.8 & 297 & 98.0 & \\
\hline \multicolumn{6}{|c|}{ Restriction in entering kitchen } \\
\hline Yes & 126 & 41.6 & 98 & 32.3 & \multirow{2}{*}{$<0.001$} \\
\hline No & 177 & 58.4 & 205 & 67.7 & \\
\hline \multicolumn{6}{|c|}{ Restriction in religious activities } \\
\hline Yes & 298 & 98.3 & 299 & 98.7 & \multirow{2}{*}{1.00} \\
\hline No & 5 & 1.7 & 4 & 1.3 & \\
\hline
\end{tabular}

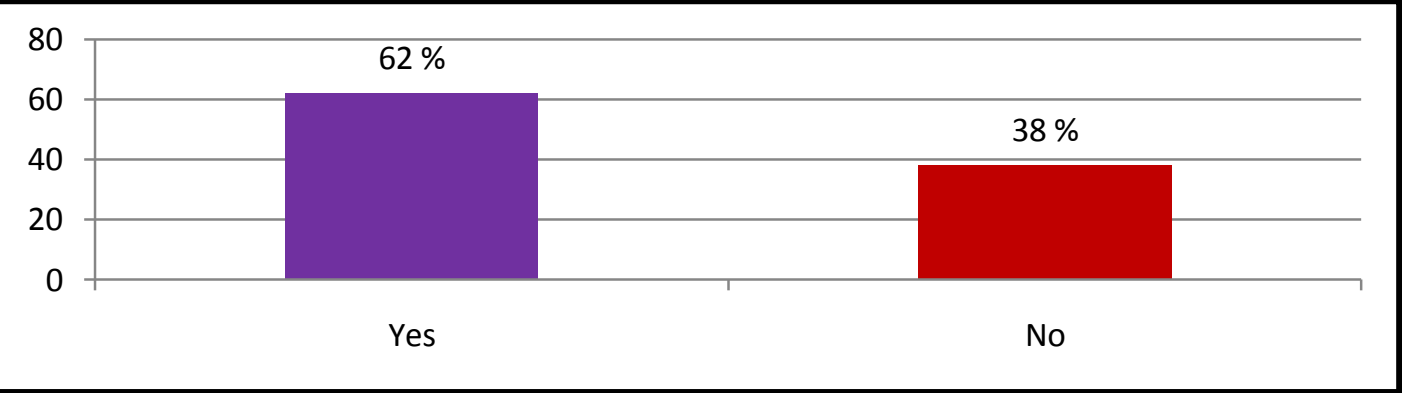

fig 1 distribution of participants according to awareness before attaining menarche

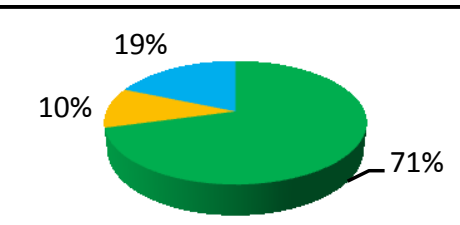

Mother $\quad$ Teacher $\square$ Friends

fig 2 distribution of participant according to source of information 